\title{
GERIATRIC SYNDROMES AND SARS-COV-2: MORE THAN JUST BEING OLD
}

\author{
I. APRAHAMIAN ${ }^{1}$, M. CESARI $^{2}$ \\ 1. Group of Investigation on Multimorbidity and Mental Health in Aging (GIMMA), Geriatrics division, Internal Medicine Department, Faculty of Medicine of Jundiaí, Jundiaí, Brazil; \\ 2. Fondazione IRCCS Ca' Granda Ospedale Maggiore Policlinico, University of Milan, Milan, Italy. \\ Corresponding author: Ivan Aprahamian, MD, MS, PhD, FACP. Group of Investigation on Multimorbidity and Mental Health in Aging (GIMMA), Division of Geriatrics, Department of \\ Internal Medicine, Faculty of Medicine of Jundiaí. 250 Francisco Telles st. ZIP 13202-550. Jundiaí, Brazil. E-mail: ivan.aprahamian@gmail.com. Twitter: @IAprahamian.

At the end of 2019, China released a warning about an outbreak of pneumonia due to unknown causes (1). It was subsequently identified as a new coronavirus, named severe acute respiratory syndrome coronavirus 2 (SARS-CoV-2), a zoonotic large size RNA-based genome virus, responsible for this infectious disease (called Covid-19) (2). The disease spread worldwide. On March 11th 2020, the World Health Organization (WHO) declared the state of pandemic, foretelling a catastrophe with major health and economic consequences. On April 3th, 1,039,166 cases of SARS-CoV-2 and 55,092 deaths have already been reported around the world (Johns Hopkins University \& Medicine Coronavirus Resource Center; https://coronavirus.jhu.edu/map.html; last access April 4th). Unfortunately, the complete clinical and epidemiological picture of Covid-19 is still unclear. This coronavirus is highly contagious (primarily airborne, but also through contact with infected surfaces), and its severity ranges from asymptomatic/ mild forms (the majority) to very severe cases (3). Currently, we are facing several challenges of difficult solution, such as lack of hospital and intensive care beds, shortage of personal protective equipment for health professionals, the loneliness and economic problems of isolated people, and the race for a vaccine and effective treatments.

\section{Older adults affected by SARS-Cov-2: What we have seen until now}

The most severe cases seem to be presented by older adults and individuals with comorbidities (in particular, hypertension, diabetes, and cardiorespiratory diseases). Today, the largest body of evidence comes from China, where the prevalence of severe illness has been reported in $16 \%$ of the cases (4). Two large cohort studies from China documented a Covid-19 prevalence of $15.1 \%$ and $26.2 \%$ in persons aged 60 years and older; about one third of the cases was found to be severely affected by the disease, with a case fatality rate around 5\% (almost five times higher than younger adults) $(5,6)$. In the United States, fatality has also reported to increase with age (10-27\% in persons aged 85 years or older; $3-11 \%$ in those between 65 and 84 years; $1-3 \%$ in persons aged 55 to 64 years; and $1-3 \%$ in younger individuals) (7). The situation in Italy has been reported to be even more dramatic with case fatality rates of $35.6 \%$ and $52.3 \%$ for individuals in their $70 \mathrm{~s}$ and $80 \mathrm{~s}$, respectively (8).
Long-term care facilities (LTCF) pose a particular challenge to public health systems. Typically, a high number of frail and vulnerable older adults lives in this environment. A LTCF situated in the King County (State of Washington, United States) reported 167 cases of Covid-19 (101 residents, 50 health care professionals, and 16 visitors) on February 28th. Case fatality rate for residents was $33.7 \%$. After 20 days, at least 30 LTCFs identified one confirmed case of Covid-19 in the King County (9).

Clinically, older adults present similar symptoms of SARSCov-2 compared with younger individuals. Fever is usually one of the first symptoms, followed by cough and shortness of breath (10). Nevertheless, frail older adults can present atypical symptoms, as we usually see in normal routine for other conditions. Inflammatory biomarker levels tend to be lower or do not show major differences from what reported in younger adults (10). At the same time, older individuals are more likely to present with higher Pneumonia Severity Index, more acute respiratory distress syndrome, and acute organ dysfunction (10). Furthermore, lung lesions usually appear particularly severe in older adults. Tomographic findings show a more extensive bilateral ground-glass pattern of lung involvement, peripheric ground-glass opacity and consolidation, and interlobular septal, subpleural line and pleural thickening. Alveolar and interstitial involvement are two times more intense than in younger adults (11).

\section{Geriatric principles of care to help overcoming this pandemic}

As long as age is (arguably) considered a risk factor for case-fatality, it is not surprising the onset of ageism-driven countermeasures against Covid-19. Vertical isolation (i.e. isolate older people) is discussed in some countries during or after the peak incidence of Covid-19. In this scenario, geriatric principles seem of utmost importance for adequate care of older people, but are frequently considered beyond the scope of action of clinicians or restricted to a group of specialized physicians. As geriatricians, we are struggling to rise our voice because we cannot forget what we know.

Older patients are surely at increased risk for severe SARSCoV-2, but age per se may not be the main contributor to this evidence. The older population is characterized by high prevalence of multimorbidity, frailty, and alterations of the 
biological background (e.g., the so-called phenomenon of inflamm-aging); all aspects that can complicate the course of disease, much more than the mere number of years lived. Moreover, the presence of geriatric syndromes, especially physical disability and cognitive impairment, may play an additional role at worsening the prognosis and increasing the risk of adverse outcomes related to Covid-19. Nonetheless, important measures of public health like social isolation may have significant physical and mental consequences in older individuals, such as depression, anxiety, and decompensation of chronic diseases. Finally, exclusively looking at age for driving clinical decision represents a clear oversimplification of the complex and heterogeneous process of aging. A pandemic situation does not justify the use of cut-points based on chronological age as guidance of clinical decisions; this is not but ageism, and is wrong. In this time of crisis, geriatricians must shed light to better support care of the most vulnerable individuals and help at overcoming this moment.

\section{The point of view of a geriatrician: What can I do for the older persons?}

Several measures can be drawn from the geriatricians' expertise and principles of geriatric medicine. There are opportunities to implement virtuous and effective models that should be considered, even by other specialties. Here are few examples:

1. Interdisciplinary hospital teams. Geriatricians are used to manage multiple, concomitant health conditions. They work in different clinical settings (i.e. acute care, post-acute care, home care, LTCF, palliative care), and transversally integrate several biomedical specialties. Geriatricians have developed models for screening patients who should be taken care with adapted/modified interventions that are tailored on the individual's priorities, values, and reserves. Since many patients admitted to the hospital are today older persons, it seems logical to promote the integration of care and multidisciplinarity with the aim of converting traditional models towards new ones more inclusive of geriatric principles, especially in front of a pandemic affecting multiple areas of the person's health.

2. Screening for frailty. One way to properly allocate care resources (especially in a time of scarcity) and estimate the person's prognosis is to measure the frailty status (instead of chronological age). Non-specialized personnel can also serve to this purpose, relying on easy instruments capturing the pre-illness status of the individual, like the Clinical Frailty Scale (12) or the FRAIL questionnaire (13).

3. Prevention of in-hospital iatrogenic conditions. Older adults with multimorbidity and geriatric syndromes are more complex to manage when hospitalized and tend to experience a longer hospital stay. To shorten the hospital stay, rapid and easy-to-assess tools for the comprehensive evaluation of the individual can be useful (14). This might allow to systematically look at neglected symptoms and conditions, precociously identify targets for intervention, and installing a virtuous cycle aimed at the prevention of the negative consequences that hospital dynamics have on older persons.

4. Monitoring of cognitive function and delirium. Many patients with neuropsychiatric disorders and individuals at high risk for delirium are still part of the population arriving to the hospital during the Covid-19 crisis. The 4AT instrument takes less than 2 minutes and can easily be used to monitor inpatients and promptly recognize acute cognitive dysfunction (15), a major risk factor for negative outcomes.

5. Test for SARS-CoV-2 and implement social countermeasures. Social distancing and isolation are crucial for flattening the epidemiological curves describing the outbreak. However, older adults may need special support to adhere to these recommendations. Online technologies, regular medical monitoring (also potentially on remote), psychological therapies (e.g., cognitive behavioral or mindfulness therapies), phone calls from/to the loved ones and healthcare personnel, and in-person contact (of course, respecting the recommendations coming from the public health authorities) might be useful for providing social support and avoiding depressive symptomatology (16). It is indeed worth to remind the close relationship existing between frailty and social aspects $(17,18)$, a link particularly true in this period of emergency.

6. Careful monitoring of LTCF. The American Geriatrics Society (AGS) and the British Geriatrics Society (BGS) published specific recommendations to support the fight against SARS-CoV-2 in LTCF. The ABCDs by the AGS emphasized the need to be aware of atypical Covid-19 symptoms, increase vigilance due to the high rates of mild and asymptomatic people, identify and contain outbreaks with proper care and isolation, and take decisions on staff and care-level organization (19). The BGS specially addressed the intensive clinical monitoring, the frailty assessment, and the development of online multidisciplinary care networks (20).

7. Promotion of physical activity. The lockdown applied to many countries and the isolation at home are particularly dangerous for frail older persons. A vicious cycle triggered by sedentariness might deteriorate the health status and start the disabling cascade (21). Dedicated programs as Vivifrail (22) might help in this context by educating people and healthcare professionals at promoting physical activity.

\section{Conclusions}

We are at war. The enemy is microscopic, extremely contagious, clinically unpredictable (kills the fit as well as the frail, the young as the old), and poses a huge threat to modern way of life and health systems. Everyone is fundamental to win the battle: from adhering to self-isolation for preventing the virus dissemination, up to the management of patients 


\section{THE JOURNAL OF FRAILTY \& AGING}

in primary care or at the hospital emergency services. Every patient must be equally considered as a person. Human values should be restored, and geriatricians might contribute with their passion and expertise at caring for older people. Let us help.

Conflict of interest: None declared by the authors

\section{References}

1. World Health Organization. Pneumonia of unknown cause - China. 2020 (https:// www.who.int/csr/don/05-january-2020-pneumonia-of-unkown-cause-china/en/).

2. Lu R, Zhao X, Li J, et al. Genomic characterisation and epidemiology of 2019 novel coronavirus: implications for virus origins and receptor binding. Lancet 2020;395:565-574

3. World Health Organization. Novel coronavirus - China. 2020 (https://www.who.int/ csr/don/12-january-2020-novel-coronavirus-china/en/)

4. Guan WJ, Ni ZY, Hu Y, et al. China Medical Treatment Expert Group for Covid-19. Clinical Characteristics of Coronavirus Disease 2019 in China. N Engl J Med. 2020 Feb 28. doi: 10.1056/NEJMoa2002032. [Epub ahead of print].

5. Yang Y., Lu Q.B., Liu M.J., et al. Epidemiological and clinical features of the 2019 novel coronavirus outbreak in China. Med Rxiv 2020, [Epub ahead of print]. DOI https://doi.org/10.1101/2020.02.10.20021675

6. Liu Y, Gayle AA, Wilder-Smith A, et al. The reproductive number of COVID-19 is higher compared to SARS coronavirus. J Travel Med 2020 [Epub ahead of print]. doi:10.1093/jtm/taaa021.

7. Severe Outcomes Among Patients with Coronavirus Disease 2019 (COVID-19) - United States, February 12-March 16, 2020. MMWR Morb Mortal Wkly Rep 2020;69:343-346. DOI: http://dx.doi.org/10.15585/mmwr.mm6912e2external icon.

8. Onder G, Rezza G, Brusaferro S. Case-Fatality Rate and Characteristics of Patients Dying in Relation to COVID-19 in Italy. JAMA. 2020 Mar 23. doi:10.1001/ jama.2020.4683. [Epub ahead of print]

9. McMichael TM, Currie DW, Clark S, et al. Epidemiology of Covid-19 in a Long Term Care Facility in King County, Washington. N Engl J Med. 2020 Mar 27. doi: 10.1056/NEJMoa2005412.[Epub ahead of print]

10. Liu K, Chen Y, Lin R, Han K. Clinical features of COVID-19 in elderly patients: A comparison with young and middle-aged patients. J Infect. 2020 Mar 27. pii: S0163 4453(20)30116-X. doi: 10.1016/j.jinf.2020.03.005. [Epub ahead of print]

11. Zhu T, Wang Y, Zhou S, Zhang N, Xia L. A Comparative Study of Chest Computed
Tomography Features in Young and Older Adults With Corona Virus Disease (COVID-19). J Thorac Imaging. 2020 Mar 31. doi: 10.1097/RTI.0000000000000513. [Epub ahead of print]

12. Dent E, Morley JE, Cruz-Jentoft AJ, et al. Physical frailty: ICFSR International Clinical Practice Guidelines for identification and management. J Nutr Health Aging 2019;23(9):771-787.

13. Aprahamian I, Arico de Almeida GV, de Vascocellos Romanin CF, et al. Frailty could predict death in older adults after admission to emergency department? A 6-month prospective study from a middle-income country. J Nutr Health Aging 2019;23:641-647.

14. Aliberti MJR, Covinsky KE, Apolinario D, et al. 10-Minute Targeted Geriatric Assessment Predicts Disability and Hospitalization in Fast-Paced Acute Care Settings. J Gerontol A Biol Sci Med Sci. 2019 Sep 15;74(10):1637-1642. doi:10.1093/gerona/glz109.

15. Shenkin SD, Fox C, Godfrey M, Siddiqi N, et al. Delirium detection in older acute medical inpatients: a multicentre prospective comparative diagnostic test accuracy study of the 4AT and the Confusion Assessment Method. BMC Med. $2019 \mathrm{Ju}$ 24;17(1):138

16. Armitage R, Nellums LB. COVID-19 and the consequences of isolating the elderly Lancet Public Health. 2020 Mar 19. pii: S2468-2667(20)30061-X. doi:10.1016/ S2468-2667(20)30061-X. [Epub ahead of print]

17. Andrew MK, Dupuis-Blanchard S, Maxwell C, et al. Social and societal implications of frailty, including impact on Canadian healthcare systems. J Frailty Aging. 2018;7(4):217-223. doi:10.14283/jfa.2018.30

18. Gutierrez-Robledo L, Avila-Funes J. How to include the social factor for determining frailty? J Frailty Aging. 2012;1(1):13-17.

19. D'Adamo H, Yoshikawa T, Ouslander JG. Coronavirus Disease 2019 in Geriatrics and Long-term Care: The ABCDs of COVID-19. J Am Geriatr Soc. 2020 Mar 25. doi:10.1111/jgs.16445. [Epub ahead of print]

20. British Geriatrics Society. COVID-19: Managing the COVID-19 pandemic in care homes. 2020. https://www.bgs.org.uk/resources/covid-19-managing-the-covid-19pandemic-in-care-homes

21. de Kerimel J, Tavassoli N, Lafont C, et al. How to Manage Frail Older Adults in the Community? Proposal of a Health Promotion Program Experienced in a City of 16,638 Inhabitants in France. J Frailty Aging. 2018;7(2):120-126.

22. Izquierdo M. [Multicomponent physical exercise program: Vivifrail]. Nutr Hosp. 2019;36(Spec No2):50-56. doi:10.20960/nh.02680 